\title{
Erbium-doped chalcogenide glass thin film on silicon using femtosecond pulsed laser with different deposition temperatures
}

\author{
K. S. Albarkaty ${ }^{1}$ E. Kumi-Barimah ${ }^{1}$ (I) C. Craig ${ }^{2}$. D. Hewak ${ }^{2} \cdot$ G. Jose ${ }^{1} \cdot$ J. Chandrappan ${ }^{1}$
}

Received: 5 September 2018 / Accepted: 27 November 2018 / Published online: 5 December 2018

(c) The Author(s) 2018

\begin{abstract}
The properties of $\mathrm{Er}^{3+}$-doped gallium lanthanum sulphide thin films prepared on a silicon substrate by femtosecond pulsed laser deposition were studied as a function of process temperature. The films were characterised using transition electron microscopy imaging, X-ray diffractometry, Raman spectroscopy, fluorescence spectroscopy, and UV-Vis-NIR spectroscopy. The results show that by increasing the substrate temperature, the deposited layer thickness increases and the crystallinity of the films changes. The room temperature photoluminescence and lifetimes of the ${ }^{4} \mathrm{I}_{13 / 2} \rightarrow{ }^{4} \mathrm{I}_{15 / 2}$ transition of $\mathrm{Er}^{3+}$ are reported in the paper.
\end{abstract}

\section{Introduction}

Chalcogenide glasses consist of chalcogen elements such as sulphur, selenium, and tellurium from the Group VI of the periodic table, and then mixed with other additive elements such as germanium (Ge), arsenic (As), antimony $(\mathrm{Sb})$, and gallium $(\mathrm{Ga})[1,2]$. These glasses have numerous applications in the near-infrared (NIR) and mid-infrared (MIR), especially the high transparency window from 1 to $10 \mu \mathrm{m}$ make them ideal for passive optical device applications [3-6]. When incorporated with rare earth ions such as ytterbium $(\mathrm{Yb})$, erbium (Er), neodymium $(\mathrm{Nd})$, thulium $(\mathrm{Tm})$, praseodymium (Pr), and holmium (Ho), they offer additional applications in long-wavelength light-emitting and amplification devices [2-4]. Furthermore, an extension of these materials study into the MIR wavelength would be suitable for active optical devices (e.g. IR fibre-optic amplifiers operating in the $2-10 \mu \mathrm{m}$ range) and a wide range of spectroscopy (e.g. diffuse reflectance and absorption) and sensing (e.g. fibre-optic chemical sensor systems) of applications [7-9]. These applications benefit integration of chalcogenide glass-based active and passive components into a single substrate, which would eventually reduce the device

E. Kumi-Barimah

preeku@leeds.ac.uk

1 School of Chemical and Process Engineering, University of Leeds, Leeds LS2 9JT, UK

2 The Optoelectronics Research Centre, University of Southampton, Southampton SO17 1BJ, UK footprint and cost [10]. For instance, Ga-La-S glass has been known and studied extensively for many years as an alternative glass to toxic As and Ge-chalcogenide-based compounds. An inherent low phonon energy makes them attractive for rare earth doping for reducing the rate of non-radiative recombination and enhancing the radiative efficiency of the rare earth ions emissions [11-13]. These glasses also support high doping concentration of the rare earth ions, leading to high refractive index $(n=2.4-3.0)$ and low-loss transmission glasses for photonic device engineering. Ye et al. [13] have demonstrated high fluorescence efficiency of Er-doped Ga-La-S glass at $1.54 \mu \mathrm{m}$, which has clear advantages over silica glasses for manufacturing optical waveguide amplifiers utilising ${ }^{4} \mathrm{I}_{13 / 2} \rightarrow{ }^{4} \mathrm{I}_{15 / 2}$ transition. Frantz et al. [14] reported Er-doped Ga-La-S glass thin film on silica substrate for waveguide amplifiers operating at a wavelength of $1.5 \mu \mathrm{m}$, and a maximum optical gain of $2.8 \mathrm{~dB} / \mathrm{cm}$ at $1.5 \mu \mathrm{m}$ of the $\mathrm{Er}^{3+}$ ion transition was obtained. Furthermore, the laser action of Nd-doped $\mathrm{Ga}-\mathrm{La}-\mathrm{S}$ glass pulled into fibres with core/clad structures has been demonstrated by Schweizer et al. [15].

Various fabrication methods have been utilised to prepare rare earth ions doped/or undoped chalcogenide thin film, including chemical vapour deposition (CVD) [16, 17], spin coating [18-20], magnetron sputtering [15, 21, 22] and pulsed laser deposition (PLD) [23-26]. For example, sputtering produces films with an acceptable stoichiometric composition identical to the target material. The PLD technique has many similarities to the sputtering method and is considered as one of the most promising techniques 
capable of producing uniform thin films or multilayer structures without changing the stoichiometric composition. It is also a highly flexible system, which consists of a wide range of deposition parameters making possible to synthesise a large variety of thin films of complex chemical composition and can provide higher doping concentrations without major fluorescence and lifetime quenching. Recently, picosecond (ps) to femtosecond (fs) regimes (short and ultrashort pulse durations) PLD have been employed to fabricate thin films, and then for material processing due to their unique advantages over the conventional PLD nanosecond (ns) and microsecond (ms) pulsed lasers (long pulse durations) [27, 28]. For instance, ablation mechanism of short and ultrashort pulse PLD is quite different from long pulse lasers, because they have ablation rate of about 30-40 times higher than those of ns and ms PLDs [29]. On the other hand, the ns and ms pulse lasers such as excimer and YAG lasers induce damage through heating and melting processes, and ablation process and thermal decomposition generate considerable high-temperature gradient or heat-affected zone in bulk material with a laser-induced shock [30]. This does not provide the needed thin film quality in complex materials, as the particle size generated becomes broader and clustered. Short and ultrashort laser regime ablation leads to minimum heataffected zone and without collateral damage to the target surface [28]. When the short and ultrashort lasers' energy interacts with the target material, their energies are absorbed by free electrons on the target surface, which consists of partially ionised vapour and a plume of hot nanoparticles via fragmentation and phase explosion, and homogeneous nucleation and decomposition [30, 31].

In this paper, we employ fs-PLD to deposit high-quality $\mathrm{Er}^{3+}$-doped $\mathrm{Ga}-\mathrm{La}-\mathrm{S}$ glass thin films on a silicon substrate. The structure and optical properties of as-deposited thin films under three different temperatures are reported for possible optical waveguide applications in the NIR.

\section{Experimental setup}

In this study, Ti:sapphire fs laser (wavelength $=800 \mathrm{~nm}$, pulse repetition rate $=1 \mathrm{kHz}$, and pulse duration $=100 \mathrm{fs}$ ) shown in Fig. 1 has been employed to deposit $\mathrm{Er}^{3+}$ iondoped $\mathrm{Ga}-\mathrm{La}-\mathrm{S}$ thin film on a silicon substrate at various temperatures. The $\mathrm{Er}^{3+}$-doped $\mathrm{Ga}-\mathrm{La}-\mathrm{S}$ glass target has a composition of Ga-La-S 65:34+1 mol \% $\mathrm{Er}_{2} \mathrm{O}_{3}$ ingot from ChG Southampton Ltd. Initially, the target and the commercially available silicon substrate of dimensions $20 \mathrm{~mm}(\mathrm{~L}) \times 12 \mathrm{~mm}(\mathrm{~W}) \times 675 \mu \mathrm{m}(\mathrm{T})$ were mounted in their respective holders inside the chamber. Both target and substrate holders were allowed to rotate continuously at a constant speed of $40 \mathrm{rpm}$ and $20 \mathrm{rpm}$, respectively, while the target-to-substance distance was kept at $70 \mathrm{~mm}$. The vacuum chamber waspumped down to about $10^{-5}$ Torr to remove any water residues in the chamber and then filled at a low flow rate of $20 \mathrm{sccm}$ argon (Ar) to maintain 80

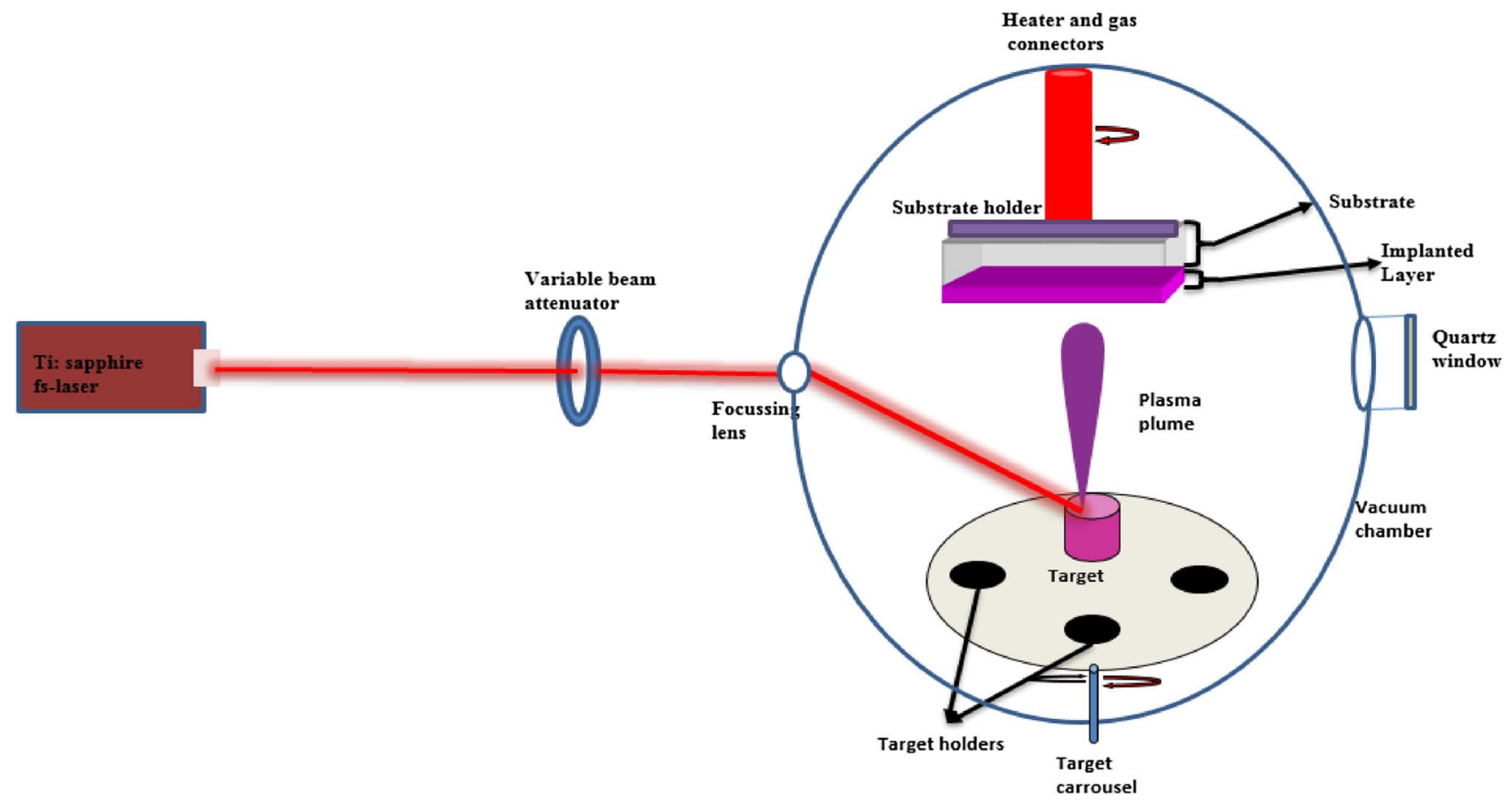

Fig. 1 Schematic setup of the fs-pulsed laser deposition system (PLD) 
mTorr throughout the process. The fs laser of pulse energy $50 \mu \mathrm{J}$ was focused onto the target material at an angle of $60^{\circ}$ to generate plasma plume directed perpendicular to the substrate surface. Three samples, GE1, GE2, and GE3, were prepared at temperatures of $25^{\circ} \mathrm{C}, 450{ }^{\circ} \mathrm{C}$ and $660{ }^{\circ} \mathrm{C}$, respectively, for $4 \mathrm{~h}$. The processed sample was kept in the vacuum chamber under the argon atmosphere and naturally cooled to room temperature.

The surface morphology and thin film thickness were obtained using an FEI Titan Themis Cubed 300 transmission electron microscopy (TEM) and high-resolution monochromated field emission gun scanning electron microscope (FEGSEM) with a precise focused ion beam (FIB) (FEI Helios G4 CX DualBeam). To investigate and understand the structural characteristics of the deposited film, Raman spectroscopy and X-ray diffraction (XRD) were utilised. A Renishaw inVia Raman spectrometer was employed to measure the Raman scattering spectra with an $\mathrm{Ar}^{+}$laser (514 nm) excitation source. Furthermore, the XRD patterns of the target sample and films were determined using a Philips X'Pert with $\mathrm{Cu} \mathrm{K} \alpha$ radiation $(\lambda=1.54056 \AA)$, at $40 \mathrm{kV}$ and $100 \mathrm{~mA}$. Each sample was scanned for $60 \mathrm{~min}$ with a diffractometer angle range from $10^{\circ}$ to $60^{\circ}$ in a step size of $0.033^{\circ}$. NIR emission spectra and lifetime of the $\mathrm{Er}^{3+}$-doped $\mathrm{Ga}-\mathrm{La}-\mathrm{S}$ bulk sample and as-deposited thin films were measured using a fluorescence spectrometer (FS920; Edinburgh Instruments, UK) equipped with semiconductor laser diode emitting $980 \mathrm{~nm}$ excitation source at room temperature. The transmission property of the thin films was measured by PerkinElmer Lambda 950 HighPerformance UV-Vis/NIR Spectrometers to estimate the optical band gap.

\section{Results and discussion}

\subsection{The structural characteristics of the $\mathrm{Er}^{3+}$-doped Ga-La-S thin films}

Figure 2a-c illustrates the TEM cross-sectional images of the films processed using an $\mathrm{Er}^{3+}$-doped $\mathrm{Ga}-\mathrm{La}-\mathrm{S}$ target at different substrate temperatures while keeping other process parameters constant. The plan view of TEM measurements reveals an average film thickness around $45 \mathrm{~nm}, 95 \mathrm{~nm}$, and $208 \mathrm{~nm}$ for samples GE1, GE2, and GE3, respectively. It can be noted that an increase in deposition substrate temperature has a significant effect on the film thickness. Figure $2 \mathrm{~d}$ shows the cross-sectional elemental mapping images obtained for GE3, which confirmed that the deposited layer consisted of the uniform distribution of the $\mathrm{Ga}, \mathrm{La}, \mathrm{S}$, and Er elements. However, there is no intermixing between the $\mathrm{Er}^{3+}$-doped $\mathrm{Ga}-\mathrm{La}-\mathrm{S}$ coating and the silicon substrate network observed in the interface.
Further quantification of a silicon substrate, a bulk glass and a thin film of the Er-doped Ga-La-S surface morphology with XRD pattern is illustrated in Fig. 3. As seen in Fig. 3, the silicon substrate exhibits two main sharp peaks centred at $36.24^{\circ}$ and $55.62^{\circ}$, which validates the crystallinity of the substrate. The more intense peak centred at $55.62^{\circ}$ is in good agreement with an ICDD (International Centre for Diffraction Data) pattern No. 00-005-0565 for silicon (not shown here), while the other peak that occurs at $36.24^{\circ}$ correlated with the ICDD diffraction pattern No. 00-0391425 corresponds to silica. On the other hand, no peak is observed from the bulk target glass; however, XRD data reveals a wide-stretched halo amorphous structure between $2 \theta=20^{\circ}$ and $30^{\circ}$.

Conversely, the XRD pattern of the $\mathrm{Er}^{3+}$-doped $\mathrm{Ga}-\mathrm{La}-\mathrm{S}$ thin film deposited at room temperature (GE1) did not possess any additional peaks compared to the silicon substrate. This clearly confirms the amorphous property of the film and further evidence is provided with discussion of Raman spectra reported in Fig. 4. However, sample GE2 prepared at higher temperature displayed two crystalline peaks centred at $2 \theta=25^{\circ}$ and $28^{\circ}$, which are not found in sample GE1. Furthermore, when the substrate temperature is increased to $660{ }^{\circ} \mathrm{C}(\mathrm{GE} 3)$, it reveals similar crystalline peaks observed in sample GE2 and three new crystalline peaks at $2 \theta=25^{\circ}, 45^{\circ}$, and $47^{\circ}$. Comparing the XRD patterns of samples GE2 and GE3 on HighScore database, these crystalline phase peaks observed are in agreement with $\mathrm{La}_{6} \mathrm{Ga}_{3.3} \mathrm{~S}_{14}, \mathrm{La}_{3} \mathrm{Ga}_{1.67} \mathrm{~S}_{7}$, and $\mathrm{LaGaS}_{3}$ which correlate with diffraction patterns No. 00-01-0815771, 00-04-005-8197, and 00-04-017-0337. A similar observation had been reported previously by Frantz et al. [14], where the author concluded that such crystal phase's formation can be attributed to quenching and/or heat treatment of the $\mathrm{Ga}-\mathrm{La}-\mathrm{S}$ target glass. Additionally, the crystallite size was calculated from the XRD data for peaks occurring around $2 \theta=25^{\circ}$ and $29^{\circ}$ through Debye-Scherer formula [32]:

$D_{(h k l)}=\frac{K}{\beta \cdot \cos \theta}$,

where $\lambda$ is the $\mathrm{X}$-ray wavelength $(0.15405 \mathrm{~nm}), \beta$ is the full width at half width at full maximum of the diffraction peak, and $K$ is a constant related to crystallite shape (0.9). The average crystallite size for samples GE2 $\left(450{ }^{\circ} \mathrm{C}\right)$ and GE3 $\left(660{ }^{\circ} \mathrm{C}\right)$ was calculated to be $\sim 5 \mathrm{~nm}$ and $15 \mathrm{~nm}$, respectively. This shows that the crystallite size increases from 5 to $15 \mathrm{~nm}$ with increasing deposition temperature from 450 to $660{ }^{\circ} \mathrm{C}$.

Figure 4 represents the Raman spectra for a pure silicon substrate, a bulk target, and thin films prepared at various temperatures when excited by a $514.5 \mathrm{~nm}$ argon laser. The silicon substrate spectrum exhibits a sharp 

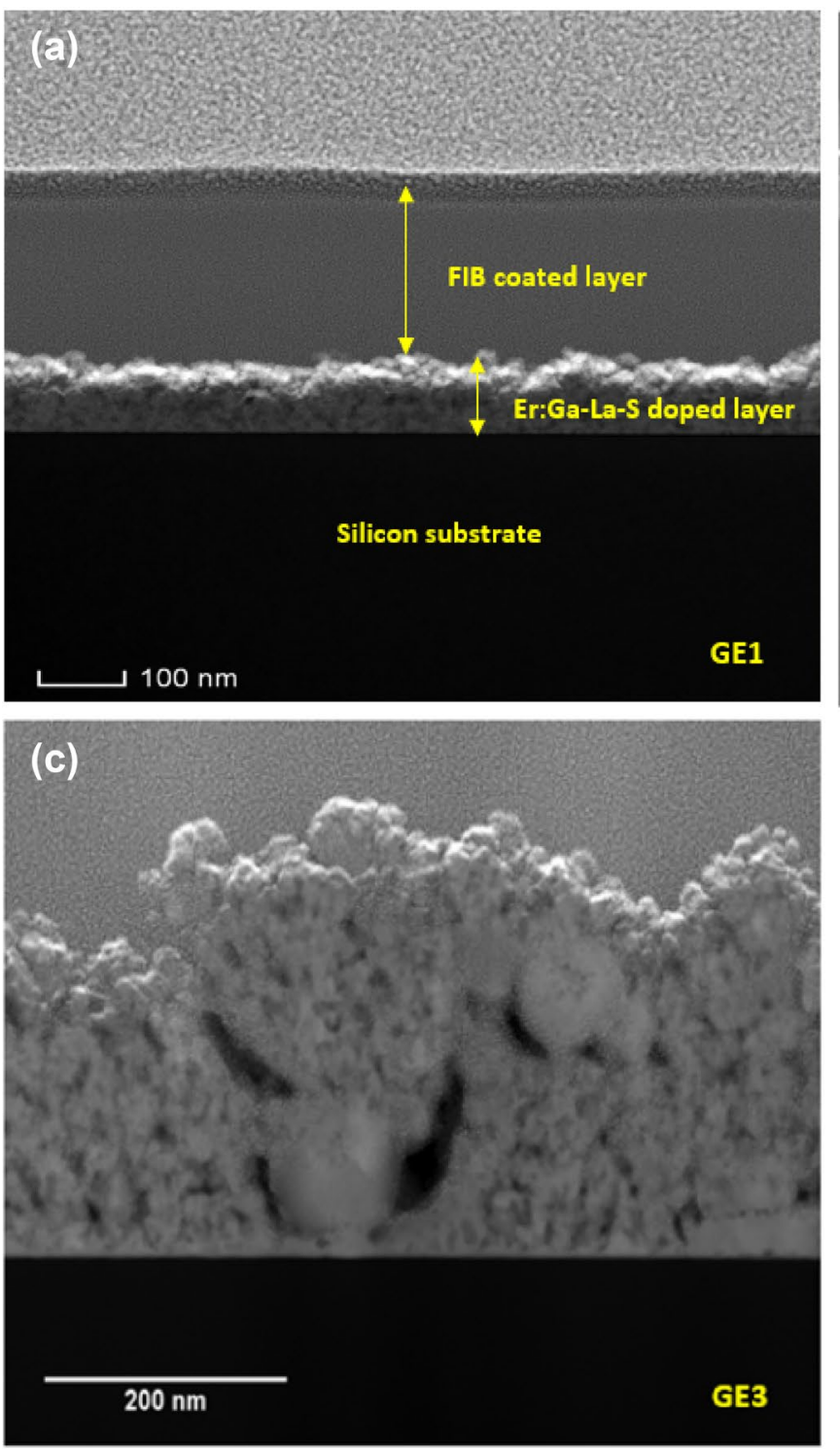

Fig. 2 a-c TEM cross-sectional images of $\mathrm{Er}^{3+}$-doped Ga-La-S thin films deposited at different substrate temperatures: a $25^{\circ} \mathrm{C}$, b $450{ }^{\circ} \mathrm{C}$, and c $660{ }^{\circ} \mathrm{C}$. d Energy-dispersive X-ray spectroscopy (EDX) ele-

peak with a characteristic band at $520 \mathrm{~cm}^{-1}$, attributed to single crystalline silicon. Furthermore, the Raman spectrum of $\mathrm{Er}^{3+}$-doped bulk Ga-La-S glass consists of three main group bands at $190-920 \mathrm{~cm}^{-1}, 920-1200 \mathrm{~cm}^{-1}$, and $1200-1800 \mathrm{~cm}^{-1}$. The broad band centred around $420 \mathrm{~cm}^{-1}$ corresponds to $\mathrm{GaS}_{4}$ tetrahedron stretching vibration modes or vibration of $\mathrm{LaS}_{8}$ structural [26] units present in amorphous $\mathrm{Ga}-\mathrm{La}-\mathrm{S}$. The broad bands at higher frequencies (centred at $1200 \mathrm{~cm}^{-1}$ and $1300 \mathrm{~cm}^{-1}$, respectively) are from $\mathrm{Er}^{3+}$ photoluminescence (PL) corresponding to ${ }^{2} \mathrm{H}_{11 / 2}{ }^{4} \mathrm{I}_{15 / 2}(547 \mathrm{~nm})$ and ${ }^{4} \mathrm{~S}_{3 / 2}{ }^{-4} \mathrm{I}_{15 / 2}(553 \mathrm{~nm})$ transitions in a glassy medium $[33,34]$.

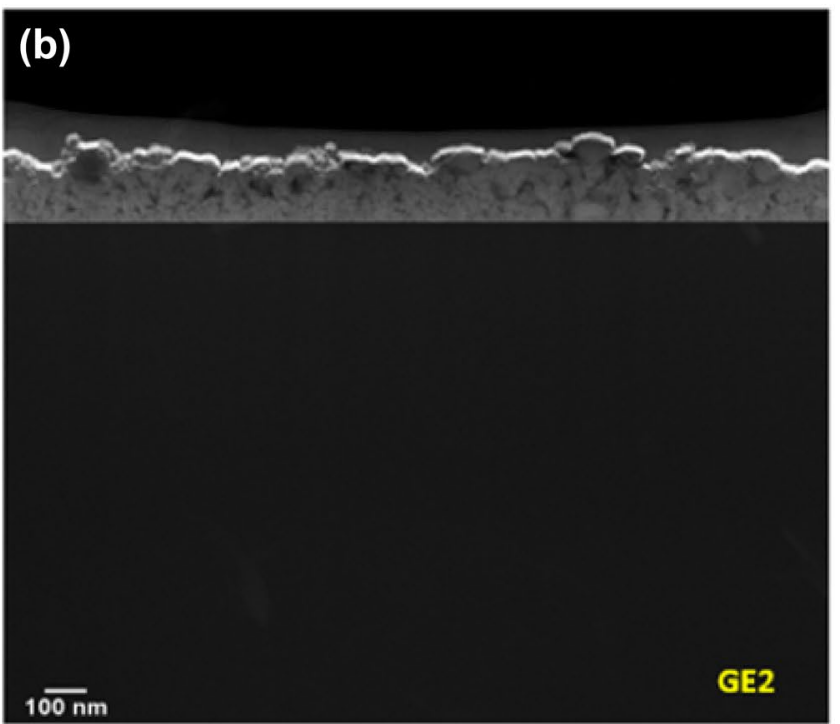

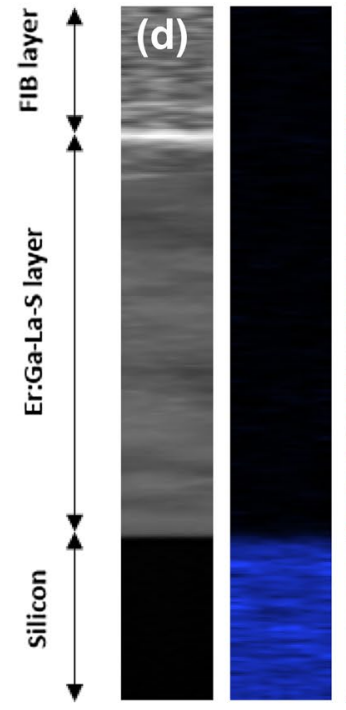

$\mathrm{Si}$

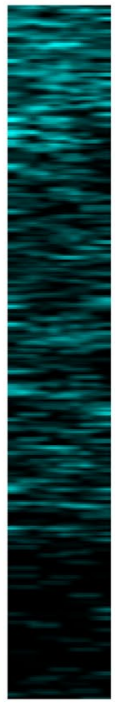

Ga

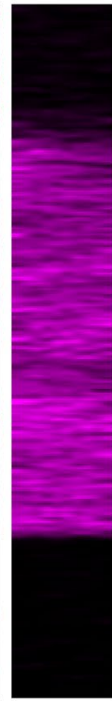

La

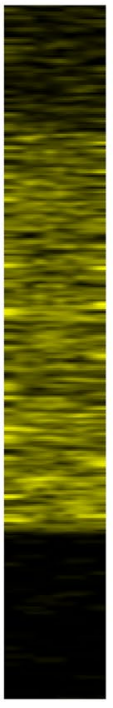

S

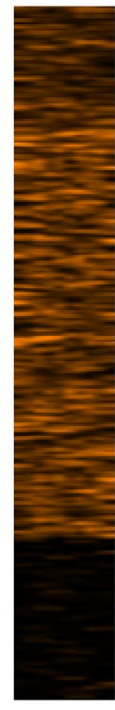

Er mental mapping obtained during cross-sectional TEM analysis of a GE3 sample prepared at $660{ }^{\circ} \mathrm{C}$

In addition to this, Raman spectra of all the thin film samples prepared by the fs-PLD were also investigated. The sample prepared at $25{ }^{\circ} \mathrm{C}$ (GE1) reveals no assigned Raman bands of the $\mathrm{Er}^{3+}$-doped $\mathrm{Ga}-\mathrm{La}-\mathrm{S}$ glass, but only a single crystalline peak in the Raman spectrum of the silicon substrate. By increasing deposition temperature of the substrate to $450{ }^{\circ} \mathrm{C}$ (GE2) and $660{ }^{\circ} \mathrm{C}$ (GE3), the Raman spectra reveal five bands with the maximum peak intensities centred around $335 \mathrm{~cm}^{-1}, 495 \mathrm{~cm}^{-1}, 644 \mathrm{~cm}^{-1}$, $1200 \mathrm{~cm}^{-1}$, and $1350 \mathrm{~cm}^{-1}$. The Raman sharper bands peaking at $335 \mathrm{~cm}^{-1}, 495 \mathrm{~cm}^{-1}$, and $644 \mathrm{~cm}^{-1}$ are correlated to the vibrations of $\mathrm{LaS}_{8}$ or $\mathrm{GaS}_{4}$ tetrahedron 


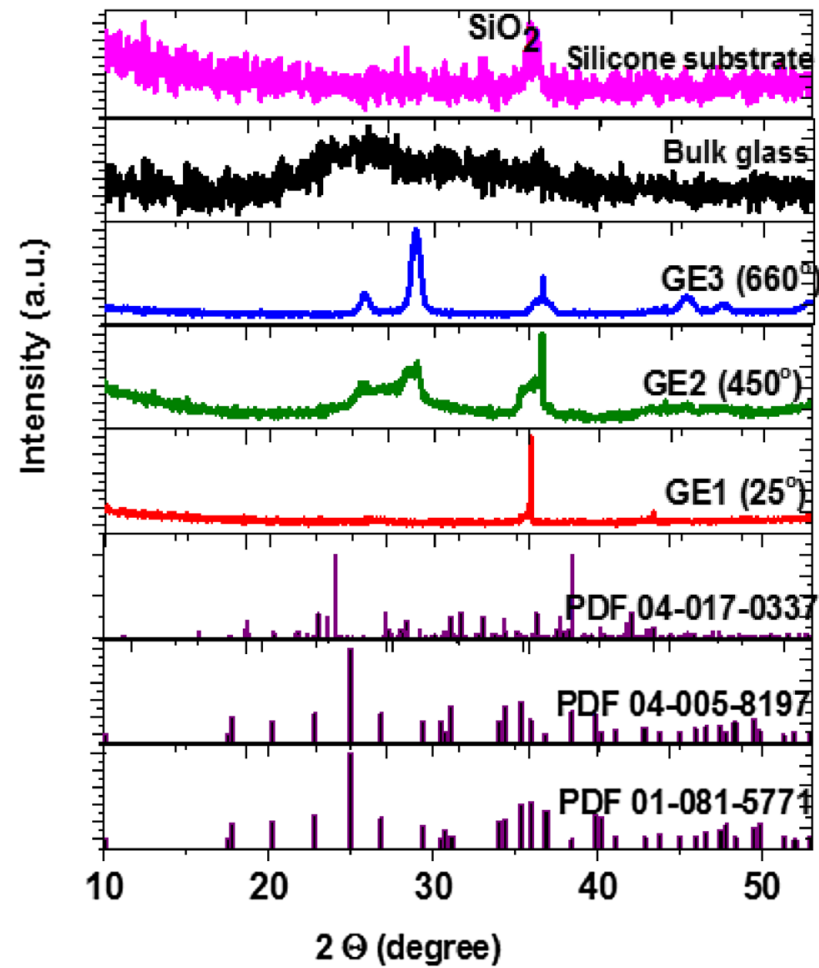

Fig. 3 XRD patterns for a pure silicon substrate (thickness $=675 \mu \mathrm{m})$, $\mathrm{Er}^{3+}$-doped $\mathrm{Ga}-\mathrm{La}-\mathrm{S}$ bulk glass, and thin films deposited on silicon at various substrate temperature

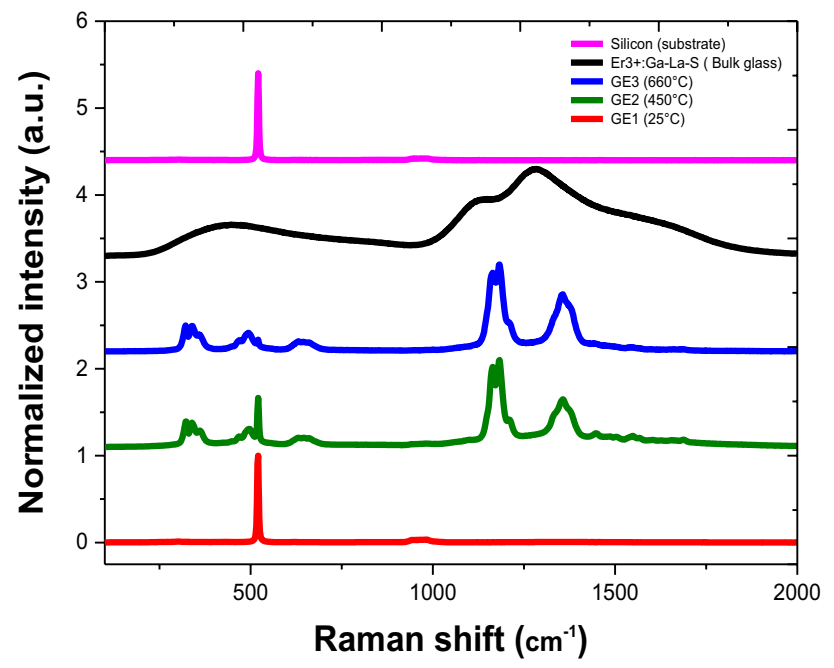

Fig. 4 Raman spectra of a pure silicon substrate (thickness $=675 \mu \mathrm{m}$ ), $\mathrm{Er}^{3+}$-doped $\mathrm{Ga}-\mathrm{La}-\mathrm{S}$ bulk glass, and thin films on silicon at various substrate temperatures

stretching vibrations, which is consistent with Lucazeau et al. [35]. However, the clearly split strong Raman bands peaking at $1200 \mathrm{~cm}^{-1}$ and $1350 \mathrm{~cm}^{-1}$ exhibit the characteristic features of $\mathrm{Er}^{3+}$-doped crystalline thin films, due to the $\mathrm{Er}^{3+}$ ions PL under $514.5 \mathrm{~nm}$ laser excitation [33].

\subsection{Optical properties of $\mathrm{Er}^{3+}$-doped Ga-La-S thin films}

The PL spectra of $\mathrm{Er}^{3+}$-doped Ga-La-S target glass and thin films are recorded at room temperature using a $980 \mathrm{~nm}$ excitation source and illustrated in Fig. 5a. The PL spectra peak around $1.54 \mu \mathrm{m}$ corresponded to the ${ }^{4} \mathrm{I}_{13 / 2}{ }^{4} \mathrm{I}_{15 / 2}$ transition of the $\mathrm{Er}^{3+}$ ions and the energy diagram is depicted in Fig. 5b. Figure 5a shows a very intense peak for all samples with spectral full width at half maximum (FWHM) $50 \mathrm{~nm}$, while the target chalcogenide glass exhibits a much broader FWHM of $\sim 75 \mathrm{~nm}$. Also, sample GE3 exhibits five multiples sharp peaks known as Stark levels, which can be attributed to the thermal population of the higher levels of the $1.54 \mu \mathrm{m}$ manifold. The presence of these transitions from Stark levels clearly confirms the crystalline phases of the doped material present in the thin film.

Table 1 shows the PL lifetime $\left(\tau_{\mathrm{f}}\right)$ measurement data for $\mathrm{Er}^{3+}$-doped Ga-La-S target glass and various thin films. The results obtained are summarised in Table 1 . The lifetime of the ${ }^{4} \mathrm{I}_{13 / 2}$ transition for the thin films decrease very rapidly from 1.82 to $0.46 \mathrm{~ms}$ with increasing deposition temperature, which confirms the changes in the local crystal field. The drop in measured fluorescence lifetime of thin film prepared at room temperature to that corresponding to the bulk glass is attributed to reabsorption that results in longer measured lifetimes in bulk glasses [36-38]. In powders and thin films of $\mathrm{Er}^{3+}$-doped chalcogenide glasses, the measured lifetimes are more accurate and comparable to radiative lifetimes [34]. Another attribute to the drop in lifetime is the higher presence of $-\mathrm{OH}$ radicals in thin film compared to bulk glasses that result in nonradioactive relaxation of the ${ }^{4} \mathrm{I}_{13 / 2}$ level, leading to a reduction in the measured lifetime. In our studies, as the deposition temperature increased, we also observed that the crystallinity of the films increased as reported in the XRD of Fig. 3. This results in more $\mathrm{Er}^{3+}$-ions being incorporated into the crystalline phases reported above, leading to $\mathrm{Er}^{3+}$ ion-ion interactions and self-quenching of photoluminescence and subsequently lower measured lifetime $[39,40]$. The drop in measured lifetime with film preparation temperature can be understood on this basis.

The transmission spectra of the thin films are measured using the UV-Vis-NIR spectrometer in the wavelength range between 320 and $2000 \mathrm{~nm}$. Thus, the absorption coefficient $(\alpha)$ spectra are determined from transmission through the thin films by the approximate expression [41, 42].

$T=(1-R)^{2} e^{-\alpha d}$,

where $T$ is the transmission, $R$ is the reflectance, and $\mathrm{d}$ is the thickness of the film, assuming that the reflectance of these thin films is very low in the photon energy range of interest.

The optical band gap energy of Er-doped Ga-La-S glass thin films prepared is calculated from the UV-Vis absorption edge by using the absorption coefficient obtained from 
Fig. 5 a Photoluminescence (PL) spectra of $1 \mathrm{~mol} \%$ $\mathrm{Er}^{3+}$-doped $\mathrm{Ga}-\mathrm{La}-\mathrm{S}$ glass and $\mathrm{Er}^{3+}$-doped $\mathrm{Ga}-\mathrm{La}-\mathrm{S}$ thin films deposited at various substrate temperatures. b Energy transfer sketch of $\mathrm{Er}^{3+}$-doped glass when pumped at $980 \mathrm{~nm}$
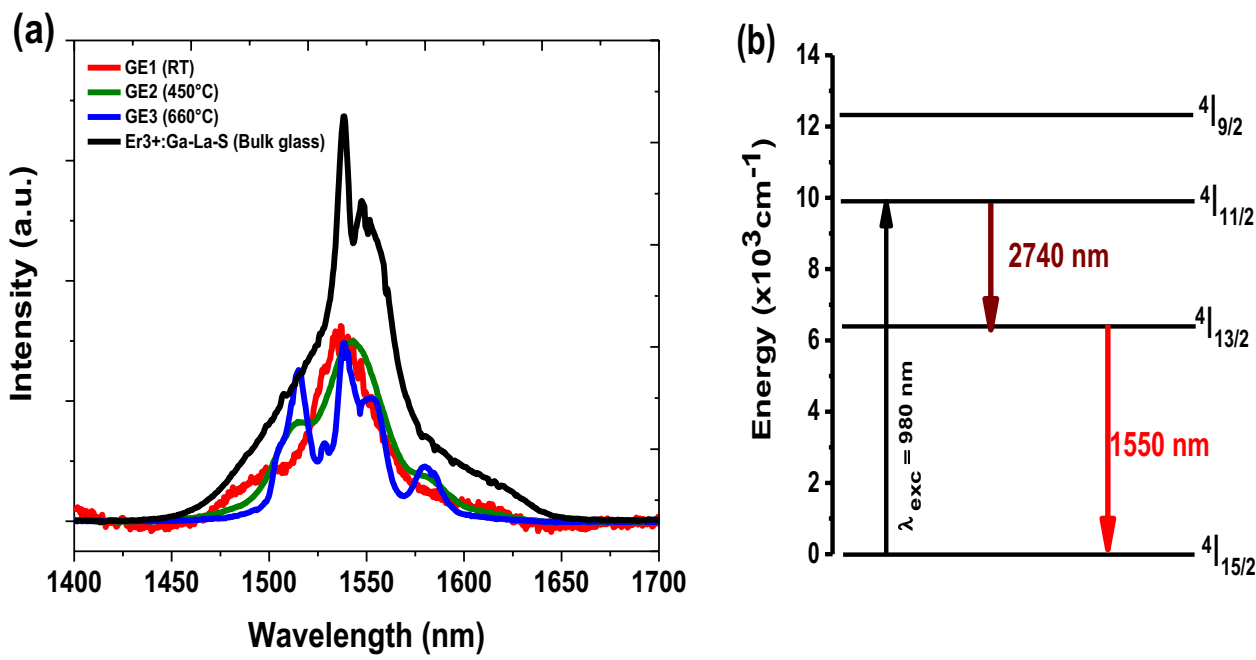

Table 1 Fluorescence lifetimes of $\mathrm{Er}^{3+}$-doped $\mathrm{Ga}-\mathrm{La}-\mathrm{S}$ samples at different substrate temperatures

\begin{tabular}{ll}
\hline $\begin{array}{l}\mathrm{Er}^{3+} \text {-doped } \\
\mathrm{Ga}-\mathrm{La}-\mathrm{S} \\
\text { samples }\end{array}$ & $\begin{array}{l}\text { Fluorescence } \\
\text { lifetime } \tau(\mathrm{ms})\end{array}$ \\
\hline Bulk glass & 4.87 \\
$\mathrm{GE} 1\left(25^{\circ} \mathrm{C}\right)$ & 1.82 \\
$\mathrm{GE} 2\left(450{ }^{\circ} \mathrm{C}\right)$ & 0.59 \\
$\mathrm{GE} 3\left(660^{\circ} \mathrm{C}\right)$ & 0.46 \\
\hline
\end{tabular}

transmission measurements and Tauc optical band gap relation $[43,44]$ :

$\alpha h v=B\left(h v-E_{\mathrm{g}}\right)^{n}$,

where $\alpha$ is the absorption coefficient, $h \nu$ is the energy of incident photons, $E_{\mathrm{g}}$ is the optical band gap, $B$ is the band tailing forbidden. $n$ symbolises the transition process which could take values $1 / 2,1,3 / 2$, or 2 for direct allowed, indirect allowed, direct forbidden, and indirect forbidden transitions depending on the electronic transitions responsible for the absorption.

The optical band gap is calculated by using $n=1 / 2$ for direct allowed from the absorption spectra, which exhibits a perfect fit for all the thin film samples. Figure $6 \mathrm{a}$ shows the plots of $(\alpha h v)^{2}$ as a function of $h v(\mathrm{eV})$. Sample GE1 prepared at low temperature has a strong absorption with $E_{\mathrm{g}}$ around $\sim 2.15 \mathrm{eV}$, and then decreases gradually with increase in deposition temperature to $E_{\mathrm{g}}$ values of $1.90 \mathrm{eV}$ and $1.75 \mathrm{eV}$ for sample GE2 and GE3 thin films, as depicted in Fig. 6b. As discussed before, when the temperature of the film increased from room temperature to $660{ }^{\circ} \mathrm{C}$, the films were found to be more crystalline. This is confirmed by the average crystallite size estimated from the XRD data for samples GE2 and GE3. Henceforth, the change in optical band gap is inversely dependent on the diameter of the crystalline size [32, 45, 46], which explains the decrease in the observed band gap $E_{\mathrm{g}}$ with increase in deposition temperature [46, 47]. Similar results have been reported previously for optical absorption of
Fig. 6 a Tauc plot as a function of photon energy and $\mathbf{b}$ optical band gap versus deposition temperature of $\mathrm{Er}^{3+}$-doped $\mathrm{Ga}-\mathrm{La}-\mathrm{S}$ glass thin films on a silicon substrate
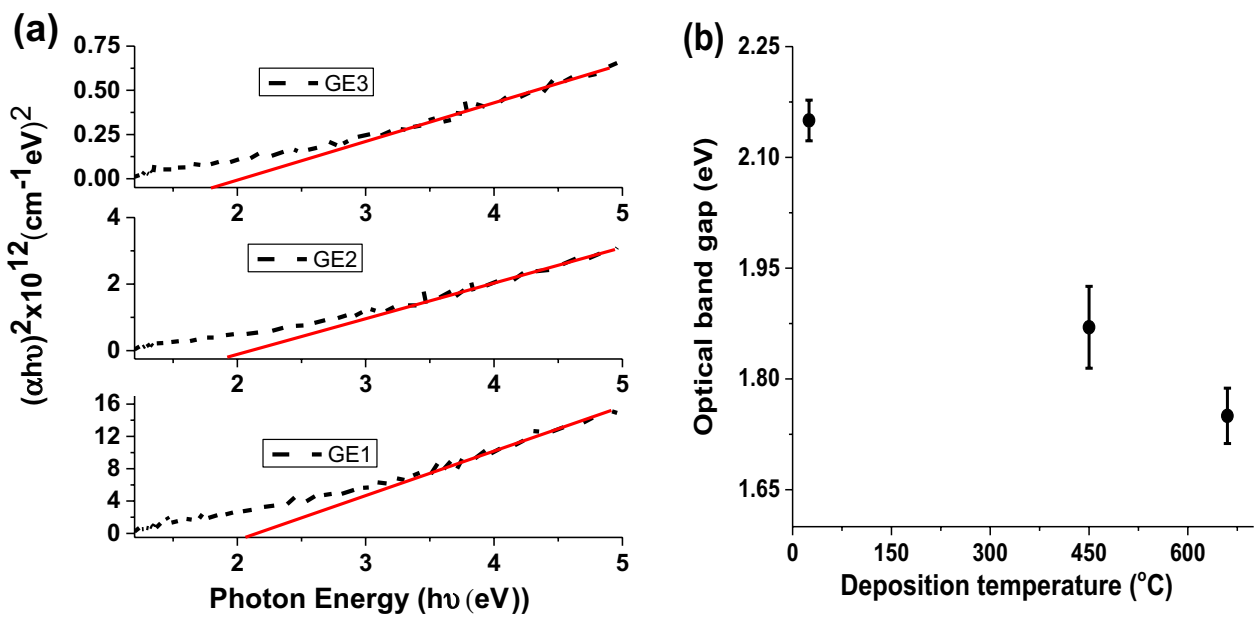
Ga-La-S thin film [12] samples fabricated by employing different deposited energy densities.

\section{Conclusions}

In summary, $\mathrm{Er}^{3+}$-doped $\mathrm{Ga}-\mathrm{La}-\mathrm{S}$ glass thin films were successfully deposited on the pure silicon substrate at various temperatures by using the fs-PLD technique. The effect of deposition temperature on the thickness and crystalline structure of the deposited films has been systematically investigated, which clearly show that an increase in deposition temperature corresponds to increase in film thickness and crystalline phases. The structural characteristics of the target chalcogenide glass changes from amorphous to crystalline phase as well. However, no intermixing and interdiffusion behaviour is observed between the silicon substrate and the deposited layer, which could link to the quality of the chalcogenide target glass, since fs-PLD-assisted induced intermixing is actually dependent on the target and substrate materials. The PL spectra of as-deposited $\mathrm{Er}^{3+}$-doped Ga-La-S chalcogenide thin films at various temperatures exhibit very intense emission signal at $1534 \mathrm{~nm}$ under a pump wavelength of $980 \mathrm{~nm}$ with FWHM at $\sim 50 \mathrm{~nm}$. On the other hand, the PL lifetime at ${ }^{4} \mathrm{I}_{13 / 2}$ transition decreases with increase in deposition temperature as discussed; clear temperature dependences of the lifetime could be associated with increasing $\mathrm{Er}^{3+}$ ion concentration in the thin films and non-radiative decay or change in the local crystal field. Finally, a large optical band gap was observed from the film prepared at the low deposition temperature. The decrease in band gap with the increase in deposition temperature is associated with increase in film thickness, as well as structural modification of the thin films. The structural and optical properties of these films show their promising use in devices such as lasers and optical amplifiers opportunities.

Acknowledgements The authors from the University of Leeds appreciate the Engineering and Physical Science Research Council (EPSRC) financial support through the SeaMatics research Grant (EP/ M015165/1). The authors acknowledge the financial support from the Saudi Ministry of Education and Umm al-Qura University (PhD scholarship for Kheir Saad Albarkaty). The University of Southampton acknowledges the support of the EPSRC through Grant EP/M015130/1 Manufacturing and Application of Next Generation Chalcogenides. There is no underpinning data which requires archiving and reasonable requests for data will be met where possible.

Open Access This article is distributed under the terms of the Creative Commons Attribution 4.0 International License (http://creativeco mmons.org/licenses/by/4.0/), which permits unrestricted use, distribution, and reproduction in any medium, provided you give appropriate credit to the original author(s) and the source, provide a link to the Creative Commons license, and indicate if changes were made.

\section{References}

1. A. Zakery, S.R. Elliott, Optical Nonlinearities in Chalcogenide Glasses and their Applications (Springer, Berlin, 2007)

2. A. B. Seddon, J. Non-Cryst. Solids 184, 44 (1995)

3. V.G. Ta'eed, N.J. Baker, L. Fu, K. Finsterbusch, M.R.E. Lamont, D.J. Moss, H.C. Nguyen, B.J. Eggleton, D.Y. Choi, S. Madden, B. Luther-Davies, Opt. Express, 15(15), 9205 (2007)

4. R.C. Schimmel, A.J. faber, H. de Waardt, G.D. Khoe, J. NonCryst. Solids 284, 188 (2001)

5. A.K. Mairaj, R.J. Curry, D.W. Hewak, Electron. Lett. 40(7), 1 (2004)

6. K. Mairaj, M.N. Petrovich, Y.W. West, A. Fu, D.W.J. Harwood, L.N. Ng, T.M. Monro, N.G. Broderick, D.W. Hewak, SPIE Fiber Opt. Sens. Technol. II Part B4204, 278 (2001)

7. M.S.B. Darby, R.E. Simpson, T.C. May-Smith, D.W. Hewak, R.W. Eason, J. Non-Cryst. Solids 354, 4582 (2008)

8. P. Bastock, C. Craig, K. Khan, E. Weatherby, J. Yao, D.W. Hewak, Properties of gallium lanthanum sulphide glass, lasers and electro-optics (CLEO, 1, 2015 conference on, IEEE Xplore), pp 2160-8989

9. D.S. Gill, R.W. Eason, C. Zaldo, H.N. Rutt, N.A. Vainos, J. NonCryst. Solids 191, 321 (1995)

10. V. Pruneri, P.G. Kazansky, D. Hewak, J. Wang, H. Takebe, D.N. Payne, Appl. Phys. Lett. 70, 155 (1997)

11. M.T. de Araujo, J.A. Medeiros Neto, A.S.B. Sombra, A.S. Oliveira, A.S. Gouveia-Neto, Opt. Mater. 7, 1 (1997)

12. R. Asal, H.N. Rutt, Opt. Mater. 8(4), 259 (1997)

13. C. C. Ye, D.W. Hewak, M. Hempstead, B.N. Samson, D.N. Payne, J. Non-Cryst. Solids 208, 56 (1996)

14. J.A. Frantz, J.S. Sanghera, L.B. Shaw, G. Villalobos, I.D. Aggarwal, D.W. Hewak, Mater. Lett. 60, 1350 (2006)

15. T. Schweizer, D.W. Hewak, D. Payne, T. Jensen, G. Huber, Neodymium-doped gallium lanthanum sulphide glass laser, in At Conference on Lasers and Electro-Optics (CLEO Europe) Conference on Lasers and Electro-Optics (CLEO Europe), CFD3, 08-13 Sep (1996), Germany

16. C. C. Huang, D.W. Hewak, Electron. Lett. 40, 863 (2004)

17. M. Churbanov, I. Scripachev, V. Shiryaev, V. Plotnichenko, S. Smetanin, E. Kryukova, Y.N. Pyrkov, B. Galagan, J. Non-Cryst. Solids 326, 301 (2003)

18. S. Song, N. Carlie, J. Boudies, L. Petit, K. Richardson, C.B. Arnold, J. Non-Cryst. Solids 355, 2272 (2009)

19. C. C. Huang, D.W. Hewak, J.V. Badding, Opt. Express 12(11), 2501 (2004)

20. N. Anscombe, D.W. Hewak, Nat. Photon. 5(8), 474 (2011)

21. D. A. Turnbull, S.J. Sanghera, V. Nguyen, I.D. Aggarwal, Mater. Lett. 58, 51 (2004)

22. M. Frumar, B. Frumarova, P. Nemec, T. Wagner, J. Jedelsky, M. Hrdlicka, J. Non-Cryst. Solids 352, 544 (2006)

23. K.E. Youden, T. Grevatt, R.W. Eason, H.N. Rutt, R.S. Deol, G. Wylangowski, Appl. Phys. Lett. 63, 1601 (1993)

24. A. Zakery, Y. Ruan, A.V. Rode, M. Samoc, B. Luther-Davies, J. Opt. Soc. Am. B 20, 1844 (2003)

25. V. Nazabal, P. Němec, J. Jedelsky, C. Duverger, J. Le Person, J.L. Adam, M. Frumar, Opt. Mater. 29, 273 (2006)

26. P. Němec, V. Nazabal, M. Pavlista, A. Moreac, M. Frumar, M. Vlcek, Mater. Chem. Phys. 117, 23 (2009)

27. T. Teghil, L.D. Alessio, A. Santagata, M. Zaccagnino, D. Ferro, D.J. Sordelet, Appl. Surf. Sci. 210, 307 (2003)

28. C. Momma, B.N. Chichkov, S. Nolte, F. von Alvensleben, A. Tünnermann, H. Welling, B. Wellegehausen, Opt. Commun. 129, 134 (1996)

29. D. Pietroy, Y. Di Maio, B. Moine, E. Audouard, Opt. Express 20(28), 29900 (2012) 
30. A. Semerok, B. Salle, J.-F. Wagner, G. Petite, Laser Part. Beams 20, 67 (2002)

31. F. Garrelie, C. Donnett, A.S., Loir, N. Benchikh, Proc. SPIE 6261, 62610L (2006)

32. F.G. Hone, F.K. Ampong, Mater. Chem. Phys. 183, 320 (2016)

33. E. Kumi-Barimah, M. W. Ziarko, N. Bamiedakis, I. H. White, R. V. Penty, G. Jose, Opt. Mater. Express 8(7), 1997 (2018)

34. Y. Jinqiu, C. Lei, H. Huaqiang, Y. Shihong, H. Yunsheng, W. Hao, J. Rare Erath's 32(1), 1 (2014)

35. G. Lucazeau, S. Barnier, A.M. Loireau-Lozac'h. Spectrochem. Acta 34A, 21 (1978)

36. A. Ravagli, N.G. Boetti, F.A. Guzman Cruz, G.A. Alzaidy, D. Pugliese, D. Milanese, D.W. Hewak, R. Soc. Chem. Adv. 8, 27556 (2018)

37. C. Kouhia, C. Craig, D.W. Hewak, S. Kasap, Opt. Mater. 41, 116 (2015)

38. C. Kouhia, S.O. Kasap, Opt. Express 16, 1343 (2008)

39. A. J. Faber, D.R. Simons, Y. Yan, H. de Waal, Proc. SPIE 2290, 80 (1994)
40. R. Morea, J. Fernandez, R. Balda, J. Gonzalo, Proc. SPIE 9744, 974402-974401 (2017)

41. T. Guang-Lei, H. Hong-Bo, S. Jian-Da, Chin. Phys. Lett. 22, 1787 (2005)

42. S. Baco, A. Chik, F.M. Yassin, J. Sci. Technol. 4, 61 (1999)

43. T.M. Mok, S.K. O'Leary, J. Appl. Phys. 102, 113525 (2007)

44. O.G. Pompilian, G. Dascalu, I. Mihaila, S. Gurlui, M. Olivier, P. Nemec, V. Nazabal, N. Cimpoesu, C. Focsa, Appl. Phys. A 117, 197 (2014)

45. M. El-Zahed, M. Dongol, Radwan, Eur. Phys. J. Appl. Phys. 17, 179-186 (2002)

46. A. El-korashy, M. A. Abdel-Rahim, H. El-Zahed, Thin Solid Films 338, 207-213 (1999)

47. H. El-Zahed, M. Dongol, M. Radwan, Eur. Phys. J. Appl. Phys. 17, 179 (2002) 